Original Research Paper

\title{
Theoretical Investigation of Two Antiemetic Drugs at DFT Level
}

\author{
${ }^{1}$ Khalil Errahmane Kanouni and ${ }^{1,2}$ Yacine Benguerba \\ ${ }^{1}$ Laboratoire Préparation, Modification et Application des Matériaux Polymériques Multiphasiques, \\ LMPMP, Department of Processes Engineering, Ferhat Abbas University, Sétif-1, Algeria \\ ${ }^{2}$ Centre de Recherche en Biotechnologie (CRBt), Constantine, Algeria
}

\author{
Article history \\ Received: 29-02-2020 \\ Revised: 22-04-2020 \\ Accepted: 12-05-2020 \\ Corresponding Author: \\ Khalil Errahmane Kanouni \\ Laboratoire Préparation, \\ Modification et Application des \\ Matériaux Polymériques \\ Multiphasiques, LMPMP, \\ Department of Processes \\ Engineering, Ferhat Abbas \\ University, Sétif-1, Algeria \\ Email: khalilkanouni@ hotmail.com
}

\begin{abstract}
The geometries and the bonding properties have been predicted for two antiemetic drugs using Density Functional Theory method (DFT). Mulliken population and frontier molecular orbital analysis with the determination of the physicochemical properties was performed using the Amsterdam Density Functional package (ADF). To calculate the exchangecorrelation energy, the Generalized Gradient Approximation of BeckePerdew (GGA-BP) was used. The most important finding is the still acceptable reliability of this method in predicting the physicochemical properties for the two organic drugs used in this study. The theoretical results obtained from the ADF software are compared with experimental ones obtained from literature. It was showed that the calculated properties were satisfactorily close to the experimental ones.
\end{abstract}

Keywords: Antiemetic Drugs, DFT, Mulliken Population, Physicochemical Properties, ADF Software, Experimental Properties

\section{Introduction}

Nowadays, the development of new drugs is becoming easier (Nicola et al., 2019) to be performed by pharmaco-chemists (Vasava et al., 2019) with simple commonly used computers and having basic notions of molecular and quantum mechanics (Henderson, 2018).

Molecular Modeling (MM) (Pal, 2020a) is a set of theoretical physical methods and computer techniques (Uto et al., 2018) that attempt to virtually mimic the behavior of molecules (Schommers, 2019). MM is the investigation of the molecular structures (Vokáčová and Pluhařová, 2019) and physical properties, using computer-based computational chemistry and graphical visualization techniques (Miao et al., 2019) to provide a plausible 3D representation under defined circumstances. MM involves the use of theoretical calculation methods (molecular mechanics (Ladefoged et al., 2019), molecular dynamics, ab initio or semi-empirical quantum mechanics, etc.) to determine the graphical representation of the geometry or the molecule configurations and to evaluate its physicochemical properties (Kwon and Moon, 2019). MM associated with an infographic representation of the stereochemistry allows to interpret the physicochemical property (Lecerf et al., 2019), to suggest new experiments (Baake et al., 2019) and to analyze results in a more critical way than the classically used experiments (Islam et al., 2019). By the way, the theoretical approaches and experimental studies are complementary (Ahmed et al., 2019).

Recently, MM has gained considerable momentum in many areas of application (Madikizela et al., 2018), namely pharmaceutical industry, biology and condensed matter (Olson, 2018). This is the set of techniques for studying and treating chemical problems on a computer without the need to go into the manipulation room to mount experiments (Jingna et al., 2019). Theoretical calculations are increasingly used in interpretations of experimental data which for some systems may be very complicated or even impossible to interpret experimentally (Piñeiro et al., 2019). They are used to predict reaction processes (Gao and Jiang, 2019) and behavior of system under very hard experimental conditions such as extreme pressure or temperature.

This work was conducted to show a fundamental and original comparison between two pharmaceutical 
molecules namely domperidone (5-chloro-1-(1-(3-(2oxo-2,3-Dihydrobenzo [D]imidazol-1-yl) propyl) piperidin-4-yl)-1H-benzo[D]imidazol-2(3H)-one) and metoclopramide (4-amino-5-chloro-N-(2-(diethylamino) ethyl)-2-methox ybenzamide).

The number of articles published in this thematic is very reduced because of the method novelty (molecular modelling) and those published in literature are limited only in experimental studies:

MADEJ and SIMPSON studied the efficacy of many antiemetic drugs and they concluded that metoclopramide significantly reduced the incidence of nausea and vomiting; domperidone decreased the incidence of postoperative nausea alone. The occurrence of extrapyramidal reactions was similar for the two drugs (Madej and Simpson, 1986).

Roila et al. (1987) have carried out a study on sixtytwo patients treated for the first time with intravenous Cyclophosphamide-Methotrexate-5FU (CMF) and they confirmed that domperidone is clearly less efficacious than metoclopramide and probably has no place in the prevention of emesis in $(\mathrm{CMF})$ treated cancer patients and they suggest that metoclopramide is more efficacious in the prevention of nausea and vomiting in CMF treated patients.

The physicochemical properties of these two molecules were determined after the geometry optimization (Dinc et al., 2019). Calculations were made with the ADF 2013 program.

\section{Results and Discussion}

Molecular geometries were Optimized using the GGABP exchange-correlation functional (Bezzerrouk et al., 2015) in the ADF program. The TZVP basis set (Myllys et al., 2016) and tight SCF convergence criteria (Sun et al., 2017) were used for calculations.

In this study the use of delocalized coordinates significantly reduces the number of geometry optimization iterations needed to optimize the molecules compared to the use of traditional Cartesian coordinates. Some of the geometries optimized were also subjected to full frequency analyses to verify the nature of the stationary points. Equilibrium geometries were characterized by the absence of imaginary frequencies.

The domperidone molecule is given in Fig. 1, where the metoclopramide is shown in Fig. 2.

\section{Mulliken Population and Frontier Molecular Orbital Analysis}

Mulliken charges are derived from the Mulliken population analysis (Yadav et al., 2020) and allow to estimate the partial atomic charges where the numerical chemistry methods are used in the calculations, as well as those based on the linear combination of atomic orbitals (Pemmaraju et al., 2018).

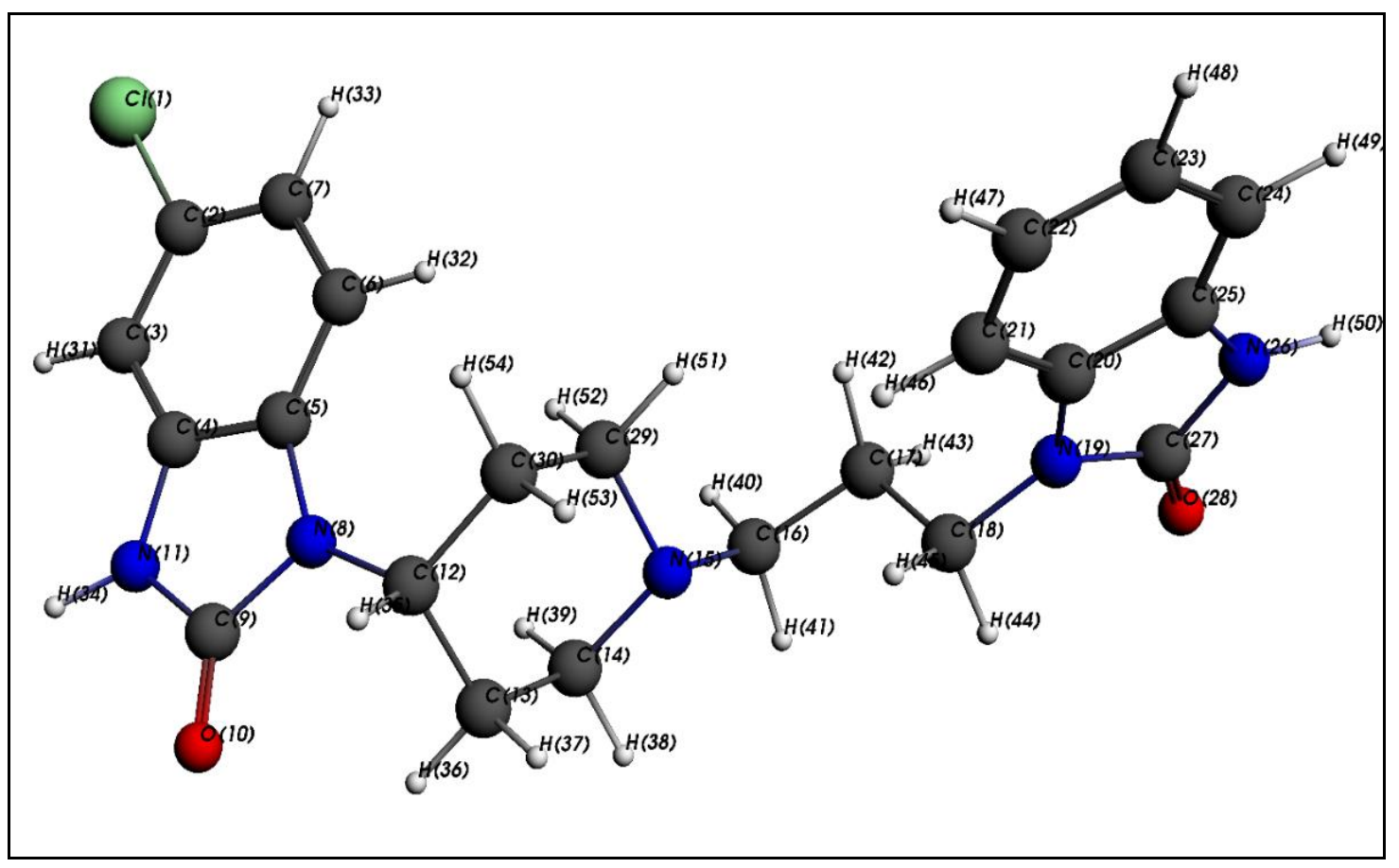

Fig. 1: The 3D optimized domperidone molecular structure 


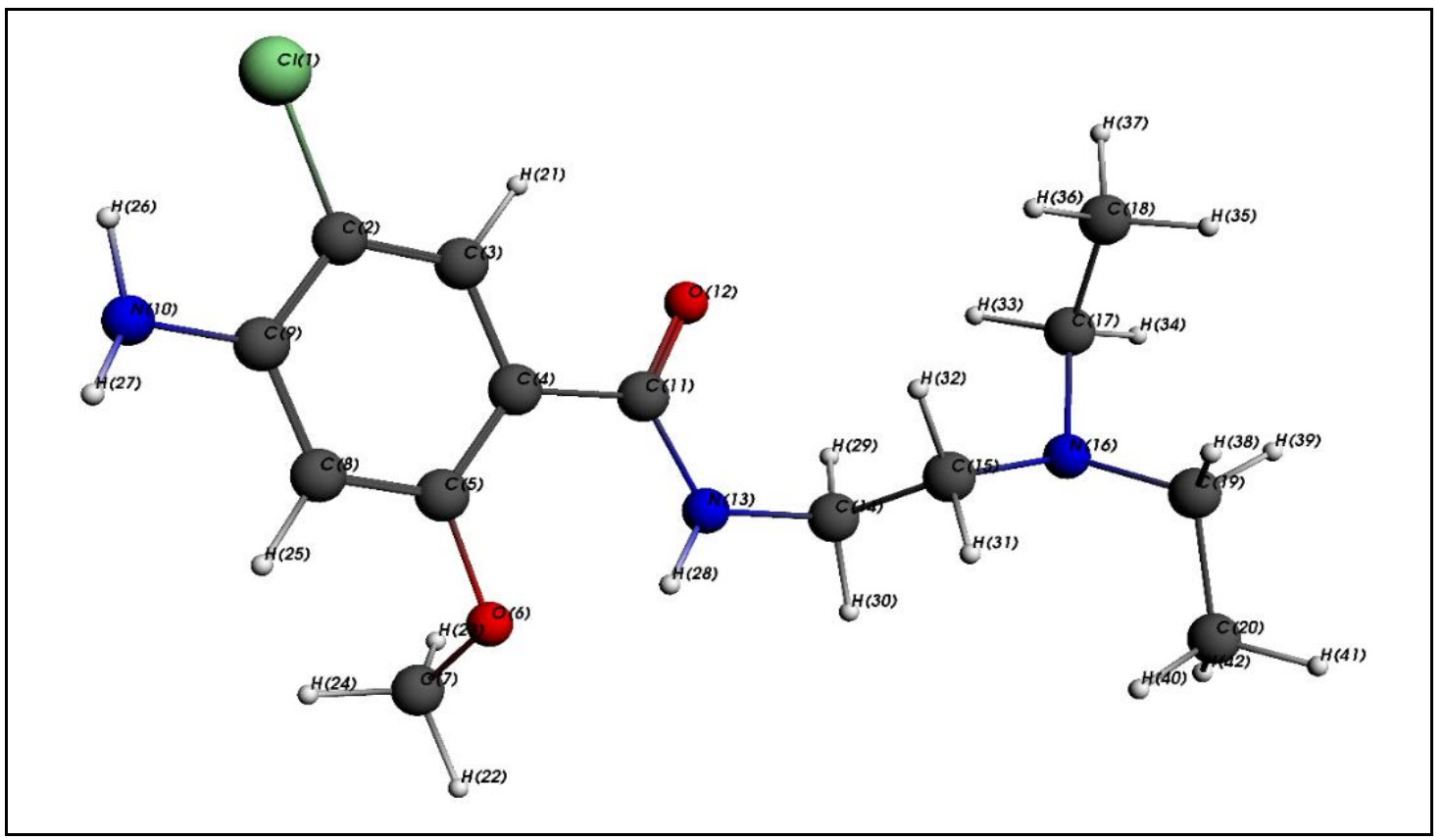

Fig. 2: The 3D optimized metoclopramide molecular structure

Four Molecular Orbitals (MOs) (Poznanski et al., 2019) were predicted: HOMO (the Highest Occupied Molecular Orbital) (Zhao et al., 2019), LUMO (the Lowest Unoccupied Molecular Orbital) (Santos et al., 2019), the second Highest Occupied Molecular Orbital (HOMO+1) (de Abreu Silva et al., 2019) and the second Lowest Unoccupied Molecular Orbital (LUMO+1). Generally, the tendency to donate electrons to an appropriate acceptor molecule is indicated by a high

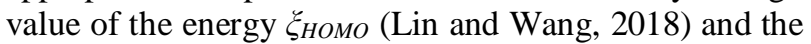
high electron accepting ability of the molecule is indicated by a low value of the energy $\xi_{L U M O}$ (Xie et al., 2019). The energies of the molecular orbitals $\xi_{\text {номо }}$ and $\xi_{\text {LUMO }}$ are used to calculate the electronic chemical potential $\mu$ (Barhoumi et al., 2019) and the global hardness $\eta$ (Arab et al., 2016) as follows:

$$
\begin{aligned}
& \mu=\left(\xi_{\text {НОМО }}+\xi_{\text {LОМО }}\right) / 2 \\
& \eta=\left(\xi_{\text {Lомо }}+\xi_{\text {НОМО }}\right) / 2
\end{aligned}
$$

Physically, $\mu$ is able to describe the escaping tendency of electrons from an equilibrium system and $\eta$ is related to the resistance towards the deformation or the polarization of the electron cloud of the molecules (Vittone et al., 2019).

The following relation express the electrophilicity index $\omega$, which is calculated using the two previous parameters: $\mu$ and $\eta$ :

$$
\omega=\mu^{2} / 2 \eta
$$

Table 1: The different energies of domperidone and metoclopramide

\begin{tabular}{lll}
\hline Energies & Domperidone & Metoclopramide \\
\hline$\xi_{\text {HOMO }}(\mathrm{Ha})$ & -0.2090 & -0.1834 \\
$\xi_{\text {LUMO }}(\mathrm{Ha})$ & -0.0778 & -0.0808 \\
$\mu(\mathrm{Ha})$ & -0.1434 & -0.1321 \\
$\eta(\mathrm{Ha})$ & 0.0656 & 0.0513 \\
$\omega(\mathrm{Ha})$ & 0.1568 & 0.1701 \\
$D$ (Debye) & 1.9099 & 4.8654 \\
\hline
\end{tabular}

The electrophilicity index expresses the ability of an electrophile to acquire an additional electronic charge (Rezende and Aracena, 2012). The notion of dipole moment in physics and chemistry is expressed by the existence of many electrostatic dipoles (Dorohoi et al., 2019). It is a heteroclite distribution of electrical charges such that the barycenter of the positive charges does not coincide with that of the negative charges (Inamdar et al., 2018). The simplest dipole is therefore a pair of two charges, of opposite signs, separated by a non-zero distance (Pal, 2020b).

According to Table 1, The chemical potential of the two molecules are very close indicating that the two molecules have an escaping tendency of electrons from an equilibrium system very similar (Slightly higher for domperidone). The two molecules were found to be very stable with $\eta$ equals 0.0656 and $0.0513 \mathrm{Ha}$, respectively. It is obvious that the domperidone has a more hardness than metoclopramide (Adly et al., 2019).

The electrophilicity index $(\omega)$ of the metoclopramide is higher than that of domperidone indicating that metoclopramide is abler to accept electrons (Wei et al., 
2019). The dipole moment of domperidone, $\mathrm{D}=1.9099$ Debye, is very close to that of water $D_{\text {water }}=1,9$ Debye but for metoclopramide, $\mathrm{D}=4.8654$ Debye. This difference in the dipole moments between these two molecules is due to the difference in the distribution of atoms (Morosanu et al., 2019) (especially the most electronegative) in the structures of their Molecules. The high value of the dipole moment of metoclopramide may increase its interaction with polar molecules like water which explains its higher solubility (Chung and Kesisoglou, 2018).
According to Table 2 giving Mulliken charges for the domperidone molecule, $\mathrm{O}(10)$ and $\mathrm{O}(28)$ have the lowest negative charge, it is noticeable that the $\mathrm{O}(28)$ oxygen atom HOMO electronic cloud is higher than that observed for $\mathrm{O}(10)$ showing that $\mathrm{O}(28)$ is the more able atom for the electrophilic attack. The highest positive charge was found for $\mathrm{C}(9)$ which is favorable for the nucleophilic attack. The HOMOs and LUMOs (Fig. 3) are mainly located over the two oxobenzimidazolyl. In this molecule, the energy gap between HOMO and LUMO/HOMO-1 and LUMO+1 is $0.1312 \mathrm{ev} / 0.147 \mathrm{ev}$, respectively.

Table 2: Mulliken charges for the domperidone molecule

\begin{tabular}{lllllllll}
\hline $\mathrm{N}^{\circ}$ & Atom & Charge & $\mathrm{N}^{\circ}$ & Atom & Charge & $\mathrm{N}^{\circ}$ & Atom & Charge \\
\hline 1 & $\mathrm{Cl}$ & -0.1030 & 19 & $\mathrm{~N}$ & -0.5726 & 37 & $\mathrm{H}$ & 0.0965 \\
2 & $\mathrm{C}$ & -0.1520 & 20 & $\mathrm{C}$ & 0.2071 & 38 & $\mathrm{H}$ & 0.0968 \\
3 & $\mathrm{C}$ & 0.0057 & 21 & $\mathrm{C}$ & -0.0749 & 39 & $\mathrm{H}$ & 0.0571 \\
4 & $\mathrm{C}$ & 0.2673 & 22 & $\mathrm{C}$ & -0.0377 & 40 & $\mathrm{H}$ & 0.0495 \\
5 & $\mathrm{C}$ & 0.1765 & 23 & $\mathrm{C}$ & -0.0413 & 41 & $\mathrm{H}$ & 0.1022 \\
6 & $\mathrm{C}$ & -0.0726 & 24 & $\mathrm{C}$ & -0.0564 & 42 & $\mathrm{H}$ & 0.1083 \\
7 & $\mathrm{C}$ & 0.0388 & 25 & $\mathrm{C}$ & 0.2490 & 43 & $\mathrm{H}$ & 0.1201 \\
8 & $\mathrm{~N}$ & -0.5698 & 26 & $\mathrm{~N}$ & -0.4763 & 44 & $\mathrm{H}$ & 0.1062 \\
9 & $\mathrm{C}$ & $\mathbf{0 . 9 9 7 5}$ & 27 & $\mathrm{C}$ & 0.9735 & 45 & $\mathrm{H}$ & 0.1217 \\
10 & $\mathrm{O}$ & $\mathbf{- 0 . 7 3 7 5}$ & 28 & $\mathrm{O}$ & $\mathbf{- 0 . 7 3 0 1}$ & 46 & $\mathrm{H}$ & 0.0616 \\
11 & $\mathrm{~N}$ & -0.4656 & 29 & $\mathrm{C}$ & -0.0103 & 47 & $\mathrm{H}$ & 0.0294 \\
12 & $\mathrm{C}$ & -0.0430 & 30 & $\mathrm{C}$ & -0.1786 & 48 & $\mathrm{H}$ & 0.0347 \\
13 & $\mathrm{C}$ & -0.1369 & 31 & $\mathrm{H}$ & 0.0775 & 49 & $\mathrm{H}$ & 0.0347 \\
14 & $\mathrm{C}$ & 0.0417 & 32 & $\mathrm{H}$ & 0.0790 & 50 & $\mathrm{H}$ & 0.1275 \\
15 & $\mathrm{~N}$ & -0.5509 & 33 & $\mathrm{H}$ & 0.0697 & 51 & $\mathrm{H}$ & 0.1290 \\
16 & $\mathrm{C}$ & 0.0195 & 34 & $\mathrm{H}$ & 0.1284 & 52 & $\mathrm{H}$ & 0.0837 \\
17 & $\mathrm{C}$ & -0.1932 & 35 & $\mathrm{H}$ & 0.1455 & 53 & $\mathrm{H}$ & 0.1311 \\
18 & $\mathrm{C}$ & 0.0110 & 36 & $\mathrm{H}$ & 0.1250 & 54 & $\mathrm{H}$ & 0.0998 \\
\hline
\end{tabular}
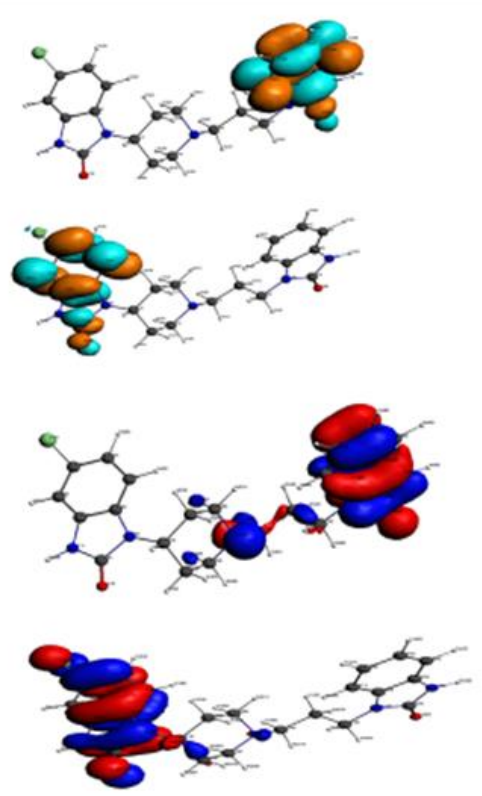

Fig. 3: Atomic orbital compositions of frontier molecular orbitals for domperidone 
According to the Table 3, the Mulliken charges for the metoclopramide molecule indicated that the oxygen atom $\mathrm{O}(6)$ has the lowest negative charge (favorable to the electrophilic attack) (Haseena et al., 2019) and the carbon atom $\mathrm{C}(11)$ has the highest positive charge (favorable to the nucleophilic attack) (Yan et al., 2019). The HOMOs and LUMOs (Fig. 4) are mainly located over the two methoxybenzamide except the HOMO that was located over the triethylamine. In this molecule, the energy gap between HOMO and LUMO/HOMO-1 and LUMO+1 is $0.1026 \mathrm{ev} / 0.1472 \mathrm{ev}$, respectively. The calculated energy gaps for the two molecules were found quite similar for HOMO-1: LUMO+1, but the HOMO: LUMO energy gap for domperidone was higher. This means that metoclopramide is more reactive than domperidone (Toppare et al., 1994). The location of HOMOs and LUMOs, showed the presence of benzyl and amine for the two molecules. This will indicate that the two molecules have a quite similar affinity to attack the active site (Chen and Wang, 2019). Regarding the electrophilicity (Table 1), it is noticed that close values were calculated for domperidone and metoclopramide. It is concluded that both molecules have the same electrophilic/nucleophilic character with respect to the receptor site (Ma and Cahard, 2007). This finding, allowed us to conclude that these two molecules attack the same receptor site (Rossi et al., 2010) since they already have the same therapeutic activity. That said, the two antiemetics (domperidone and metoclopramide) have the same effect in the human organism (Baum et al., 1984).

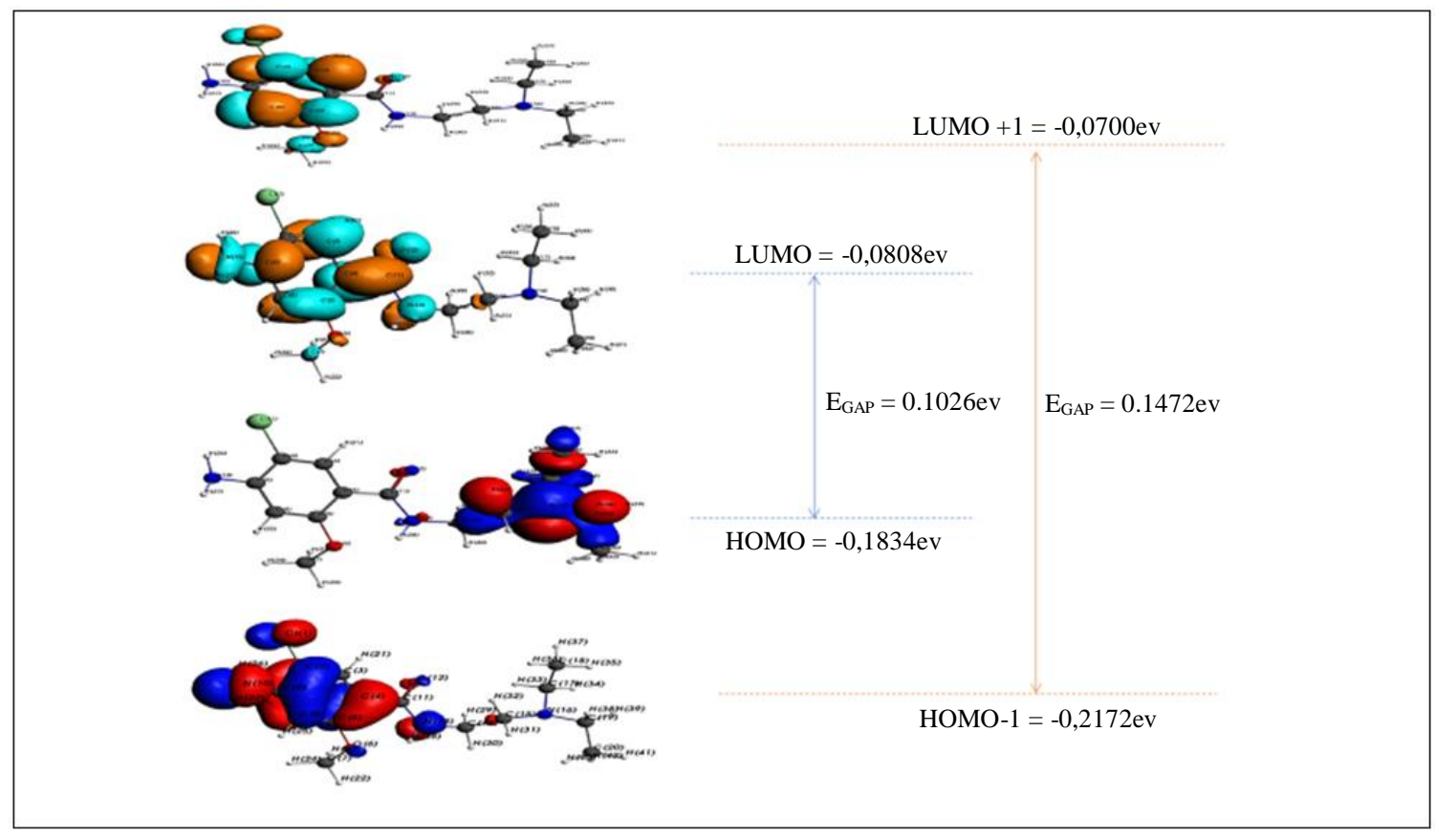

Fig. 4: Atomic orbital compositions of frontier molecular orbitals for metoclopramide

Table 3: Mulliken charges for the metoclopramide molecule

\begin{tabular}{lllllllll}
\hline $\mathrm{N}^{\circ}$ & Atom & Charge & $\mathrm{N}^{\circ}$ & Atom & Charge & $\mathrm{N}^{\circ}$ & Atom & Charge \\
\hline 1 & $\mathrm{Cl}$ & -0.1110 & 15 & $\mathrm{C}$ & 0.0013 & 29 & $\mathrm{H}$ & 0.1104 \\
2 & $\mathrm{C}$ & -0.1400 & 16 & $\mathrm{~N}$ & -0.5627 & 30 & $\mathrm{H}$ & 0.0834 \\
3 & $\mathrm{C}$ & 0.1221 & 17 & $\mathrm{C}$ & -0.0418 & 31 & $\mathrm{H}$ & 0.0912 \\
4 & $\mathrm{C}$ & -0.1883 & 18 & $\mathrm{C}$ & -0.0948 & 32 & $\mathrm{H}$ & 0.1041 \\
5 & $\mathrm{C}$ & 0.3515 & 19 & $\mathrm{C}$ & -0.0231 & 33 & $\mathrm{H}$ & 0.1260 \\
6 & $\mathrm{O}$ & $\mathbf{- 0 . 7 5 5 2}$ & 20 & $\mathrm{C}$ & -0.0541 & 34 & $\mathrm{H}$ & 0.0879 \\
7 & $\mathrm{C}$ & 0.2963 & 21 & $\mathrm{H}$ & 0.1240 & 35 & $\mathrm{H}$ & 0.0309 \\
8 & $\mathrm{C}$ & -0.0379 & 22 & $\mathrm{H}$ & 0.0424 & 36 & $\mathrm{H}$ & 0.0476 \\
9 & $\mathrm{C}$ & 0.2635 & 23 & $\mathrm{H}$ & 0.0348 & 37 & $\mathrm{H}$ & 0.0444 \\
10 & $\mathrm{~N}$ & -0.3744 & 24 & $\mathrm{H}$ & 0.0496 & 38 & $\mathrm{H}$ & 0.0452 \\
11 & $\mathrm{C}$ & $\mathbf{0 . 7 7 4 7}$ & 25 & $\mathrm{H}$ & 0.0737 & 39 & $\mathrm{H}$ & 0.1010 \\
12 & $\mathrm{O}$ & $\mathbf{- 0 . 7 3 4 3}$ & 26 & $\mathrm{H}$ & 0.1515 & 40 & $\mathrm{H}$ & 0.0337 \\
13 & $\mathrm{~N}$ & -0.4880 & 27 & $\mathrm{H}$ & 0.1142 & 41 & $\mathrm{H}$ & 0.0341 \\
14 & $\mathrm{C}$ & 0.0240 & 28 & $\mathrm{H}$ & 0.2027 & 42 & $\mathrm{H}$ & 0.0394 \\
\hline
\end{tabular}


Table 4: The physicochemical properties of domperidone

\begin{tabular}{lll}
\hline Property & Calculated & Experimental \\
\hline Vapor pressure $\left(\right.$ bar at $\left.25^{\circ} \mathrm{C}\right)$ & $8.64 * 10^{-17}$ & $\mathrm{na}^{(*)}$ \\
Boiling point $\left({ }^{\circ} \mathrm{C}\right)$ & 629.902 & 633.17 \\
Melting point $\left({ }^{\circ} \mathrm{C}\right)$ & 240.09 & 242.5 \\
Partition coefficient $(\log \mathrm{P})$ & 3.808 & 3.9 \\
pKa & 7.922 & 7.9 \\
Solubility $(\mathrm{mg} / \mathrm{l})$ & 1.003 & 0.986 \\
\hline
\end{tabular}

na(*): Not available

Table 5: Physicochemical properties of metoclopramide

\begin{tabular}{lll}
\hline Property & Calculated & Experimental \\
\hline Vapor pressure $\left(\right.$ bar at $\left.25^{\circ} \mathrm{C}\right)$ & $6.17 * 10^{-12}$ & $6,05^{*} 10^{-12}$ \\
Boiling point $\left({ }^{\circ} \mathrm{C}\right)$ & 415.38 & 418.7 \\
Melting point $\left({ }^{\circ} \mathrm{C}\right)$ & 144.21 & 147.25 \\
Partition coefficient $(\log \mathrm{P})$ & 2.592 & 2.62 \\
pKa & 9.199 & 9.27 \\
Solubility $(\mathrm{mg} / \mathrm{l})$ & 194.02955 & 200 \\
\hline
\end{tabular}

\section{Physicochemical Properties}

To calculate physicochemical properties, the COnductor-like Screening MOdel for Realistic Solvents (COSMO-RS) (Abranches et al., 2019) was used.

The computed physicochemical properties given in Tables 4 and 5 are found to be close to the experimental values. The vapor pressure given for the two molecules show the low volatility of the domperidone and metoclopramide.

The computed boiling point were found to be very high 629.9 and $415.38^{\circ} \mathrm{C}$ for domperidone and metoclopramide respectively (Ohe, 2019). The melting point was found 240.09 and $144.21^{\circ} \mathrm{C}$ for domperidone and metoclopramide respectively. It is remarkable that the temperature ranges in which the two drugs are in the liquid phase is very large. it is also noted that the melting and boiling temperatures of the metoclopramide are the lowest.

$\log \mathrm{P}$ characterize the hydrophilic or lipophilic character of a molecule (Chmiel et al., 2019) and calculated by the logarithm of the partition coefficient between octanol and water. It is used to evaluate the bioavailability of a molecule: $\log \mathrm{P}<0$, the molecule is said hydrophilic; $\log \mathrm{P}>5$, the molecule is lipophilic; A good balance is needed between the hydrophilic and hydrophobic character for an optimal biological activity $0<\log \mathrm{P}<5$ (de Oliveira et al., 2019). A molecule with an optimal biological activity is sufficiently hydrophilic to be soluble in aqueous media (blood, cytoplasm...) and in the same time it must have a hydrophobic character to pass through the membranes (Pieńko et al., 2016). It should be noted that the partition coefficients of the two molecules have optimal biological activity (Sagandykova et al., 2018) with 3.808 and 2.592 for domperidone and metoclopramide respectively.

The pKa for the two molecules is greater than 7 indicating a basic character for both molecules. That said, the basicity of metoclopramide is higher (Tang et al., 2014).
The solubility of metoclopramide is much higher than that of domperidone, which means its ease blood transport (Arnau and Vallano, 1993).

\section{Conclusion}

This novel method (theoretical study) was set out to determine some physicochemical properties like partition coefficient, solubility, pKa, etc. The experimental physicochemical properties of domperidone and metoclopramide are calculated with confidence using the GGA-BP exchange-correlation functional and the TZVP basis sets with tight SCF convergence criteria for calculations. The geometry optimization, population analysis and Mulliken charges were calculated and analyzed using the same method with the same parametrizations. This results obtained theoretically were compared with the experimental ones. The application of the theoretical methods such as molecular dynamics, allowed the determination of physicochemical properties of the two antiemetic drugs. The calculated properties values were quite close to the experimental ones especially the boiling point, the melting point and the solubility. This further study reinforces the choice of the molecular modeling as an indispensable tool in the development of drugs and pharmaceutical theoretical chemistry and leading to reduce the number of laboratories experiments.

\section{Acknowledgement}

The authors gratefully acknowledge the suggestions and comments of the anonymous referee and the editor which helped immensely to make substantial improvements to the content and presentation of the paper.

\section{Funding Information}

The authors have no support or funding to report.

\section{Author's Contributions}

All authors equally contributed in this work.

\section{Ethics}

This article is original and contains unpublished material. The corresponding author confirms that all of the other authors have read and approved the manuscript and no ethical issues involved.

\section{References}

Abranches, D.O., M. Larriba, L.P. Silva, M. Melle-Franco and J.F. Palomar et al., 2019. Using COSMO-RS to design choline chloride pharmaceutical eutectic solvents. Fluid Phase Equilibria, 497: 71-78.

DOI: 10.1016/j.fluid.2019.06.005 
Adly, O.M.I., A. Taha and S.A. Fahmy, 2019. Synthesis, characterization of binary and ternary copper(II)semicarbazone complexes: Solvatochromic shift, dipole moments and TD-DFT calculations. J. Mol. Struct., 1186: 362-376.

DOI: 10.1016/j.molstruc.2019.02.103

Ahmed, S., W. Ru, H. Han, L. Cheng and X. Bian et al., 2019. Fine molecular structure and its effects on physicochemical properties of starches in potatoes grown in two locations. Food Hydrocoll., 97: 105172-105172.

DOI: 10.1016/j.foodhyd.2019.105172

Arab, A., F. Ziari and M. Fazli, 2016. Electronic structure and reactivity of $\left(\mathrm{TiO}_{2}\right) \mathrm{n}(\mathrm{n}=1-10)$ nanoclusters: Global and local hardness based DFT study. Comput. Mater. Sci., 117: 90-97. DOI: 10.1016/j.commatsci.2016.01.031

Arnau, J.M. and A. Vallano, 1993. Gastrointestinal Drugs. In: Side Effects of Drugs Annual, Aronson, J.K. and C.J. Van Boxtel (Eds.), Elsevier, pp: 413-431.

Baake, E., A. González Casanova, S. Probst and A. Wakolbinger, 2019. Modelling and simulating Lenski's long-term evolution experiment. Theor. Popul. Biol., 127: 58-74.

DOI: $10.1016 /$ j.tpb.2019.03.006

Barhoumi, M., K. Lazaar and M. Said, 2019. DFT study of electronic and optical properties of silicene functionalized with chemical groups. J. Mol. Graph. Model, 91: 72-79.

DOI: $10.1016 /$ j.jmgm.2019.06.003

Baum, H., J. Gergely, B.L. Fanburg, 1984. Emetic and Antiemetic Drugs. In: Molecular Aspects of Medicine, Baum, H., J. Gergely, B.L. Fanburg (Eds.), Pergamon, pp: 451-477.

Bezzerrouk, M.A., M. Hassan, R. Baghdad, S. Reguieg and M. Bousmaha et al., 2015. Thermodynamic, structural and electronic, properties of $\mathrm{SnO}_{2}$ : By GGA and GGA + trans-blaha-modified BeckeJohnson (TB-mBJ) calculation. Superlattices Microstruct., 84: 80-90.

DOI: $10.1016 /$ j.spmi.2015.02.046

Chen, D. and H. Wang, 2019. HOMO-LUMO energy splitting in polycyclic aromatic hydrocarbons and their derivatives. Proc. Combust. Inst., 37: 953-959. DOI: $10.1016 /$ j.proci.2018.06.120

Chmiel, T., A. Mieszkowska, D. Kempińska-Kupczyk, A. Kot-Wasik and J. Namieśnik et al. 2019. The impact of lipophilicity on environmental processes, drug delivery and bioavailability of food components. Microchem. J., 146: 393-406.

DOI: 10.1016/j.microc.2019.01.030

Chung, J. and F. Kesisoglou, 2018. Physiologically based oral absorption modelling to study gut-level drug interactions. J. Pharm. Sci., 107: 18-23.

DOI: $10.1016 /$ j.xphs.2017.08.015 de Abreu Silva, M., C.D.B. Sette, A.S. Kiametis, L.A.S. Romeiro and R. Gargano, 2019. Molecular modeling of cardanol-derived AChE inhibitors. Chem. Phys. Lett., 731: 136591-136591.

DOI: 10.1016/j.cplett.2019.07.019

de Oliveira, G.H.O., S.B. do Nascimento, F.M. de Oliveira, V.S. Belo and L.J. de Alencar Danda et al., 2019. Systematic evaluation of the impact of solid-state polymorphism on the bioavailability of thalidomide. Eur. J. Pharm. Sci., 136: 104937-104937.

DOI: $10.1016 /$ j.ejps.2019.05.015

Dinc, F., L. Thiele and B.C. Akdeniz, 2019. The effective geometry Monte Carlo algorithm: Applications to molecular communication. Phys. Lett. A, 383: 2594-2603.

DOI: $10.1016 /$ j.physleta.2019.05.029

Dorohoi, D.O., D.H. Partenie, A.C. Calugaru, 2019. Specific and universal interactions in Benzo-[f]Quinolinium Acetyl-Benzoyl Methylid (BQABM) solutions; excited state dipole moment of BQABM. Spectrochim. Acta. A. Mol. Biomol. Spectrosc., 213: 184-191. DOI: 10.1016/j.saa.2019.01.035

Gao, M. and D. Jiang, 2019. Analysis of stochastic multimolecular biochemical reaction model with lévy jumps. Phys. Stat. Mech. Applic., 524: 601-613. DOI: 10.1016/j.physa.2019.04.218

Haseena, S., R.M. Kumar, V. Rajapandian and V. Subramanian, 2019. Interactions of thiol and alkoxy radical with coinage metal nanoclusters. Applied Surf. Sci., 487: 1409-1419.

DOI: 10.1016/j.apsusc.2019.04.151

Henderson, L., 2018. Quantum reaxiomatisations and information-theoretic interpretations of quantum theory. Stud. Hist. Philos. Sci. Part B Stud. Hist. Philos. Mod. Phys.

DOI: 10.1016/j.shpsb.2018.06.003

Inamdar, S.R., G.H. Pujar and M.S. Sannaikar, 2018. FRET from ZnSe/ZnS QDs to coumarin dyes: Role of acceptor dipole moment and QD surface states on FRET efficiency. J. Lumin., 203: 67-73.

DOI: $10.1016 /$ j.jlumin.2018.06.012

Islam, M.N., O. Körner, J.S. Pedersen, J.N. Sørensen and M. Edelenbos, 2019. Analyzing quality and modelling mass loss of onions during drying and storage. Comput. Electron. Agric., 164: 104865-104865. DOI: 10.1016/j.compag.2019.104865

Jingna, X., N. Guanhua, X. Hongchao, L. Shang and S. Qian et al., 2019. The effect of adding surfactant to the treating acid on the chemical properties of an acid-treated coal. Powder Technol. DOI: 10.1016/j.powtec.2019.08.039

Kwon, B.G. and K. Moon, 2019. Physicochemical properties of styrene oligomers in the environment. Sci. Total Environ., 683: 216-220.

DOI: $10.1016 /$ j.scitotenv.2019.05.301 
Ladefoged, L.K., T. Zeppelin and B. Schiøtt, 2019. Molecular modeling of neurological membrane proteins - from binding sites to synapses. Neurosci. Lett., Molecular Model. Neurosci.: New Windows Funct. Nervous Syst., 700: 38-49.

DOI: 10.1016/j.neulet.2018.05.034

Lecerf, M., A. Kanyavuz, S. Lacroix-Desmazes and J.D. Dimitrov, 2019. Sequence features of variable region determining physicochemical properties and polyreactivity of therapeutic antibodies. Mol. Immunol., 112: 338-346.

DOI: $10.1016 /$ j.molimm.2019.06.012

Lin, H. and Q. Wang, 2018. Non-fullerene small molecule electron acceptors for high-performance organic solar cells. J. Energy Chem., 27: 990-1016. DOI: 10.1016/j.jechem.2017.11.028

Ma, J.A. and D. Cahard, 2007. Strategies for nucleophilic, electrophilic and radical trifluoromethylations. J. Fluor. Chem., 128: 975-996. DOI: 10.1016/j.jfluchem.2007.04.026

Madej, T.H. and K.H. Simpson, 1986. Comparison of the use of domperidone, droperidol and metoclopramide in the prevention of nausea and vomiting following major gynaecological surgery. Br. J. Anaesth., 58: 884-887.

DOI: $10.1093 / \mathrm{bja} / 58.8 .884$

Madikizela, L.M., N.T. Tavengwa, H. Tutu and L. Chimuka, 2018. Green aspects in molecular imprinting technology: From design to environmental applications. Trends Environ. Anal. Chem., 17: 14-22. DOI: 10.1016/j.teac.2018.01.001

Miao, H., T. Klein, D. Kouřil, P. Mindek and K. Schatz et al., 2019. Multiscale molecular visualization. J. Mol. Biol., 431: 1049-1070. DOI: $10.1016 /$ j.jmb.2018.09.004

Morosanu, A.C., D.G. Dimitriu and D.O. Dorohoi, 2019. Excited state dipole moment of the fluorescein molecule estimated from electronic absorption spectra. J. Mol. Struct., 1180: 723-732.

DOI: 10.1016/j.molstruc.2018.12.057

Myllys, N., J. Elm and T. Kurtén, 2016. Density functional theory basis set convergence of sulfuric acid-containing molecular clusters. Comput. Theor. Chem., 1098: 1-12.

DOI: 10.1016/j.comptc.2016.10.015

Nicola, A.M., P. Albuquerque, H.C. Paes, L. Fernandes and F.F. Costa et al., 2019. Antifungal drugs: New insights in research and development. Pharmacol. Ther., 195: 21-38.

DOI: $10.1016 /$ j.pharmthera.2018.10.008

Ohe, S., 2019. A prediction method of vapor pressures by using boiling point data. Fluid Phase Equilibria, 501: 112078-112078.

DOI: 10.1016/j.fluid.2019.01.018
Olson, A.J., 2018. Perspectives on structural molecular biology visualization: From past to present. J. Mol. Biol., 430: 3997-4012. DOI: 10.1016/j.jmb.2018.07.009

Pal, S., 2020a. Computational Molecular Biology. In: Fundamentals of Molecular Structural Biology, Pal, S. (Ed.), Academic Press, pp: 465-480.

Pal, S., 2020b. Chemical Basis of Biology. In: Fundamentals of Molecular Structural Biology, Pal, S. (Ed.), Academic Press, pp: 61-82.

Pemmaraju, C.D., F.D. Vila, J.J. Kas, S.A. Sato and J.J. Rehr et al., 2018. Velocity-gauge real-time TDDFT within a numerical atomic orbital basis set. Comput. Phys. Commun., 226: 30-38.

DOI: 10.1016/j.cpc.2018.01.013

Pieńko, T., M. Grudzień, P.P. Taciak and A.P. Mazurek, 2016. Cytisine basicity, solvation, $\log \mathrm{P}$ and $\log \mathrm{D}$ theoretical determination as tool for bioavailability prediction. J. Mol. Graph. Model., 63: 15-21.

DOI: 10.1016/j.jmgm.2015.11.003

Piñeiro, Á., E. Muñoz, J. Sabín, M. Costas and M. Bastos et al., 2019. AFFINImeter: A software to analyze molecular recognition processes from experimental data. Anal. Biochem., 577: 117-134. DOI: 10.1016/j.ab.2019.02.031

Poznanski, R.R., L.A. Cacha, A.Z.A. Latif, S.H. Salleh and J. Ali et al., 2019. Molecular orbitals of delocalized electron clouds in neuronal domains. Biosystems, 183: 103982-103982.

DOI: 10.1016/j.biosystems.2019.103982

Rezende, M.C. and A. Aracena, 2012. Electrophilicity and solvatochromic reversal of pyridinium phenolate betaine dyes. Chem. Phys. Lett., 542: 147-152. DOI: 10.1016/j.cplett.2012.06.017

Roila, F., M. Tonato, C. Basurto, V. Minotti and E. Ballatori et al., 1987. Double-blind controlled trial of the antiemetic efficacy and toxicity of Methylprednisolone (MP), Metoclopramide (MTC) and Domperidone (DMP) in breast cancer patients treated with i.v. CMF. Eur. J. Cancer Clin. Oncol., 23: 615-617.

DOI: $10.1016 / 0277-5379(87) 90255-0$

Rossi, A.G.Z., R.C. Teixeira Gomes, M. de Jesus Simões, R. dos Santos Simões and P.B. Oliveira et al., 2010. Effects of metoclopramide-induced hyperprolactinemia on the prolactin receptor of murine endometrium. Fertil. Steril., 93: 1643-1649. DOI: 10.1016/j.fertnstert.2009.02.021

Sagandykova, G.N., P.P. Pomastowski, R. Kaliszan and B. Buszewski, 2018. Modern analytical methods for consideration of natural biological activity. TrAC Trends Anal. Chem., 109: 198-213. DOI: $10.1016 /$ j.trac.2018.10.012 
Santos, E.S., V.S. Reis, L. Guimarães and C.S. Nascimento, 2019. Molecular wires formed from native and push-pull derivatives polypyrroles and $\beta$ cyclodextrins: A HOMO-LUMO gap theoretical investigation. Chem. Phys. Lett., 730: 141-146. DOI: 10.1016/j.cplett.2019.05.058

Schommers, W., 2019. Theoretical and Computational Methods. In: Basic Physics of Nanoscience, Schommers, W. (Ed.), Elsevier, pp: 91-202.

Sun, Z., T. Zhu, X. Wang, Y. Mei and J.Z.H. Zhang, 2017. Optimization of convergence criteria for fragmentation methods. Chem. Phys. Lett., 687: 163-170. DOI: 10.1016/j.cplett.2017.08.059

Tang, Y.Y., Y. Du, J. Ni, Y.S. Ma and X.M. Lin et al., 2014. Relaxant effects of metoclopramide and magnesium sulfate on isolated pregnant myometrium: An in vitro study. Int. J. Obstet. Anesth., 23: 131-137.

DOI: 10.1016/j.ijoa.2013.11.004

Toppare, M.F., Y. Laleli, D.A. Şenses, F. Kitapci and I.S. Kaya et al., 1994. Metoclopramide for breast milk production. Nutr. Res., 14: 1019-1029.

DOI: 10.1016/S0271-5317(05)80256-8

Uto, T., Y. Kodama, T. Miyata and T. Yui, 2018. Molecular dynamics simulations of theoretical cellulose nanotube models. Carbohydr. Polym., 190: 331-338. DOI: 10.1016/j.carbpol.2018.03.004

Vasava, M.S., S.G. Nair, S.K. Rathwa, D.B. Patel and H.D. Patel, 2019. Development of new drugregimens against multidrug-resistant tuberculosis. Indian J. Tuberc., 66: 12-19. DOI: 10.1016/j.ijtb.2018.07.004

Vittone, E., J. Garcia Lopez, M. Jaksic, M.C. Jimenez Ramos and A. Lohstroh et al., 2019. Determination of radiation hardness of silicon diodes. Nucl. Instrum. Methods Phys. Res. Sect. B Beam Interact. Mater. At., 449: 6-10.

DOI: $10.1016 /$ j.nimb.2019.04.032
Vokáčová, Z.S. and E. Pluhařová, 2019. Understanding structure and dynamics of organic liquid mixtures by molecular simulations. J. Mol. Liq., 288: 110778-110778. DOI: 10.1016/j.molliq.2019.04.055

Wei, Z., W. Li, D. Zhao, Y. Seo and R. Spinney et al., 2019. Electrophilicity index as a critical indicator for the biodegradation of the pharmaceuticals in aerobic activated sludge processes. Water Res., 160: 10-17. DOI: 10.1016/j.watres.2019.05.057

Xie, L., J. Xiao, L. Wu, W. Zhang and Z. Ge et al., 2019. Synthesis and photovoltaic properties of small molecule electron acceptors with twin spiro-type core structure. Dyes Pigments, 168: 197-204.

DOI: 10.1016/j.dyepig.2019.04.064

Yadav, S.B., S.S. Sonvane and N. Sekar, 2020. Novel blue-green emitting NLOphoric triphenylamineimidazole based donor- $\pi$-acceptor compound: Solvatochromism, DFT, TD-DFT and non-linear optical studies. Spectrochim. Acta. A. Mol. Biomol. Spectrosc, 224: 117421-117421. DOI: $10.1016 /$ j.saa.2019.117421

Yan, M., Z. Zhang, J. Zhou, W. Li and C. Zhang et al., 2019. Synthesis and DFT studies of novel aryloxymaleimides via nucleophilic substitution of tosyloxy group. J. Mol. Struct., 1189: 155-160.

DOI: 10.1016/j.molstruc.2019.04.020

Zhao, X., C. Chen, Q. Sun, Y. Li and H. Yu, 2019. Molecular structure optimization design of inhibitors based on frontier orbitals theory. Applied Surf. Sci., 494: 895-907.

DOI: $10.1016 /$ j.apsusc.2019.07.248 